\title{
Basic Study of Bacteria Inactivation at Low Discharge Voltage by Using Microplasmas
}

\author{
Kazuo Shimizu, Member, IEEE, Masahiro Yamada, Masaki Kanamori, and Marius Blajan
}

\begin{abstract}
Inactivation of microorganisms, such as Escherichia coli, by exposure to a microplasma is experimentally investigated. A microplasma is an atmospheric-pressure nonthermal plasma. Microplasmas, which generate high-intensity electric fields, can be formed using relatively low discharge voltages $(0.7-1.1 \mathrm{kV})$ across small discharge gaps $(0-100 \mu \mathrm{m})$. The key benefits of the practical application of exposure to a microplasma are as follows: 1) the low discharge voltage and 2) the simple apparatus because a vacuum enclosure is not required. Hence, the apparatus for generating a microplasma could be relatively small and inexpensive and could be integrated into a portable device. The ozone generated by a microplasma at a low power level was measured, although the specific power density of the microplasma was larger than that of large-scale conventional plasmas. The emission spectra of the microplasma discharge in $\mathrm{N}_{2}$ was measured: 1) to confirm the UV light emission and 2) to identify the active chemical species generated by the microplasma discharge. The emission spectra was also measured with the presence of water droplets. The UV light from the microplasma discharge showed excited nitrogen molecules and $\mathrm{OH}$ radicals. In this paper, two cultures of bacteria, i.e., gram-negative Escherichia coli $\mathrm{HB} 101$ and gram-positive Bacillus subtilis JCB 20036 were the target microorganisms to be inactivated. In the experiments reported here, the number of bacteria decreased after microplasma treatment. The inactivation rate increases as the discharge voltage increases. Escherichia coli is completely inactivated when air is used as carrier gas at a plasma discharge voltage of $1.05 \mathrm{kV}$. Using nitrogen as carrier gas, the highest inactivation rate is $77 \%$ at a discharge voltage of $1.15 \mathrm{kV}$. In addition, Bacillus subtilis is inactivated with a rate of $97 \%$ at $1.07 \mathrm{kV}$ with air as carrier gas. Using nitrogen as carrier gas and a discharge voltage of $1 \mathrm{kV}$ results in an inactivation rate of $70 \%$ of bacteria. The inactivation of microorganisms by microplasma may be due to several factors either individually or in combination of the following: 1) the excited molecules and ions; 2) ozone; 3) high electrical fields; and 4) UV light. The effect of active
\end{abstract}

Paper 2008-EPC-189.R2, presented at the 2008 Industry Applications Society Annual Meeting, Edmonton, AB, Canada, October 5-9, and approved for publication in the IEEE TRANSACTIONS ON INDUSTRY APPLICATIONS by the Electrostatic Processes Committee of the IEEE Industry Applications Society. Manuscript submitted for review November 20, 2008 and released for publication July 27, 2009. First published January 15, 2010; current version published March 19, 2010. This work was supported in part by the Ministry of Education, Science, Sports and Culture under Grant-in-Aid for Young Scientists (A), 2007.

K. Shimizu is with the Innovation and Joint Reseach Center, Shizuoka University, Hamamatsu 432-8561, Japan (e-mail: shimizu @ cjr.shizuoka.ac.jp).

M. Yamada and M. Kanamori were with the Innovation and Joint Reseach Center, Shizuoka University, Hamamatsu 432-8561, Japan. They are now with Toshiba Carrier Corporation, Tokyo 108-0074, Japan (e-mail: yamada0430@ gmail.com; goldmori@hotmail.com).

M. Blajan was with the Electronics and Electrostatics Research Unit, Laboratory of Automatics and Industrial Informatics, University of Poitiers, 16021 Poitiers, France. He is now with the Innovation and Joint Reseach Center, Shizuoka University, Hamamatsu 432-8561, Japan (e-mail: blajanmarius@ yahoo.com).

Color versions of one or more of the figures in this paper are available online at http://ieeexplore.ieee.org.

Digital Object Identifier 10.1109/TIA.2010.2040053 species such as $\mathrm{OH}$ radicals may also be important since all the bacteria were carried within a small water droplet in between the electrodes.

Index Terms-Bacillus subtilis, electric fields, Escherichia coli, inactivation, microplasma, ozone.

\section{INTRODUCTION}

$\mathbf{T}$ RADITIONALLY, heat sterilization [1], irradiative sterilization [2], and chemical treatment [3] are used for sterilization. If these methods were applied to food, for example, concerns would include the deterioration of flavor by the heating and contamination by residual chemicals. Therefore, an effective sterilization method is needed that is safe and does not affect the foods' flavor. Recently, sterilization methods using various kinds of discharges and plasmas have been investigated [4]-[16]. The plasma can be applied to heat-sensitive materials without any thermal damage, and it can also be applied to human skin without any sensation of pain.

Nonthermal plasmas generated by dielectric-barrier discharges at atmospheric pressure have several different mechanisms occurring simultaneously that may be germicidal: UV radiation which may reach into the vacuum UV region, and streamers which contain high-energy electrons, which generate short-lived chemically reactive radicals by electron impact dissociation of molecular gases [11]. Nonthermal plasma with $\mathrm{H}_{2} \mathrm{O}$ addition shows higher sterilization rates than those of dry processes [12]. Atmospheric-pressure glow discharge with helium results in a higher efficiency of Bacillus subtilis spore inactivation than that of a helium-oxygen plasma plume [13]. Nonthermal plasmas for biodecontamination, chemical decontamination, plasma decontamination in medicine, and electric discharges for plasma decontamination have been studied and reported by various groups [14].

In this paper, the inactivation by microplasma was investigated, in which the discharge voltage and power were lower in comparison with conventional plasma sterilization. Two cultures of bacteria were used to carry out the inactivation experiments: gram-negative Escherichia coli HB101 and grampositive Bacillus subtilis JCB 20036 cultures, respectively. In order to investigate the impact of different radical species formed in the microplasmas, the experiments were performed using two different carrier gases: air and nitrogen.

\section{About Microplasma}

Fig. 1 shows a schematic image of the electrodes used in the experiments. A ferroelectric material covered the surface 


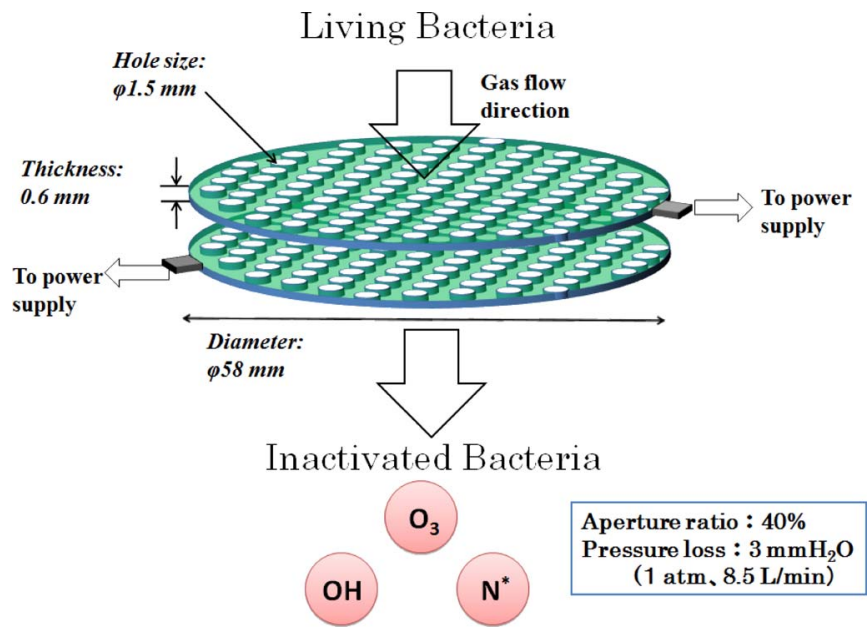

Fig. 1. Schematic image of microplasma electrodes. The pressure loss between the electrodes is very small.

TABLE I

Minimum Sparking Voltage and Discharge GAP FOR VARIOUS GASES

\begin{tabular}{|c|c|c|}
\hline Gas & $\begin{array}{c}\text { Minimum } \\
\text { sparking } \\
\text { voltage [V] }\end{array}$ & $\begin{array}{c}\text { Discharge gap } \\
{[\mu \mathrm{m}]}\end{array}$ \\
\hline Air & 330 & 7.5 \\
\hline Oxygen & 450 & 9.2 \\
\hline Nitrogen & 275 & 9.9 \\
\hline
\end{tabular}

of the stainless-steel electrodes [17], [18]. The diameters of the electrodes are $\varnothing 58 \mathrm{~mm}$, and the thickness of each electrode is $0.6 \mathrm{~mm}$.

The thickness of the dielectric barrier covering the base metal is about $100 \mu \mathrm{m}$. The electrodes have holes $(\varnothing 1.5 \mathrm{~mm})$, and their aperture ratio is about $40 \%$. The pressure loss is relatively low (about 3-mm $\mathrm{H}_{2} \mathrm{O}$ at a gas-flow rate of $8.5 \mathrm{~L} / \mathrm{min}$ ). By applying an alternating voltage to the electrodes, streamers are formed between the electrodes.

In the experiments reported here, the discharge gap between the electrodes is set to $10 \mu \mathrm{m}$ in order to minimize the discharge voltage at atmospheric pressure based on Paschen's law.

Table I shows the sparking voltages and the discharge gaps for air, nitrogen, and oxygen.

Fig. 2 shows a schematic image of the active species generated by the microplasma between the electrodes and the exposure of the living bacteria to the microplasma causing inactivation. A suspension of living bacteria in water was sprayed perpendicular to the electrode. The living bacteria were carried through the holes by the carrier gas. Due to the small discharge gap between electrodes $(0-10 \mu \mathrm{m})$ and the direction of the gas flow, few of the bacteria enter the discharge gap between electrodes, and most pass through the holes. The few bacteria that enter the narrow zone between the electrodes attach to the surface of the electrodes and are lost from the flow of the carrier gas. The bacteria and their colonies that were counted on the nutrient medium were exclusively those bacteria which passed the holes.

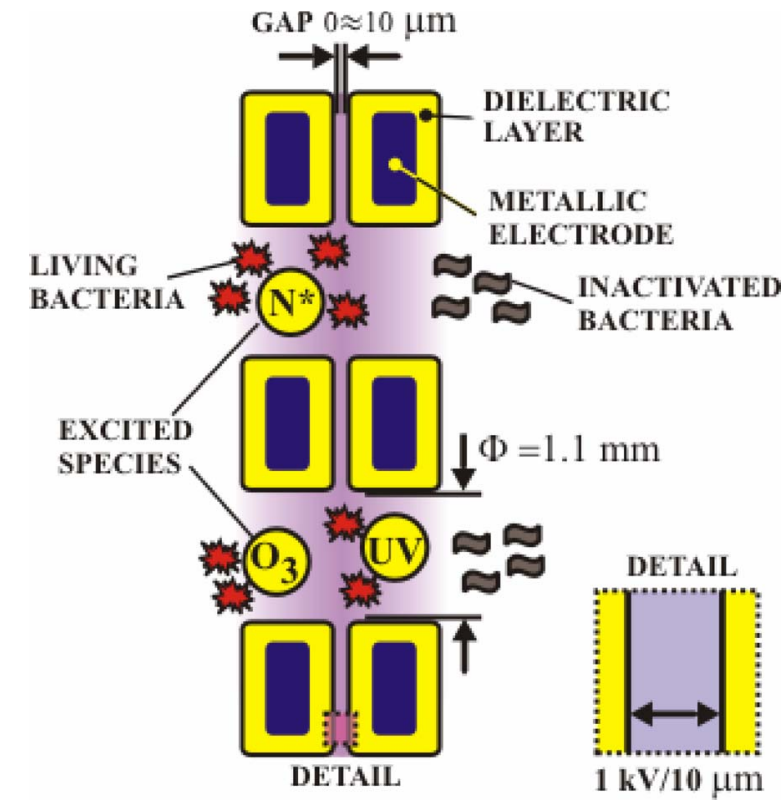

Fig. 2. Schematic image of the inactivation processes of microplasma between the electrodes.

A microplasma is a dielectric-barrier discharge characterized by a large number of short-lived microdischarges. Each microdischarge has an almost cylindrical plasma channel of about $100-\mu \mathrm{m}$ radius [19].

Thus, the electrodes have a plasma area of $0.314 \mathrm{~mm}^{2}$ located around each hole. The area in which the plasma does not occur is $0.64 \mathrm{~mm}^{2}$ located in the center of each holes. In this region, the excited nitrogen molecules, nitrogen ions, ozone, and the UV light interact with the bacteria resulting in inactivation, as shown in Fig. 2 and Section VII [20], [21]. It is reported that each bacterium can be attacked and degraded by the ozone and the active species generated by the plasma [11].

The dielectric barrier with a thickness of $100 \mu \mathrm{m}$ has an assumed specific dielectric constant of $\varepsilon_{r 1}=10^{4}$. The electric displacement field inside the capacitor formed by the two dielectric layers and the air gap is constant; in the air gap, the electric field is $E_{2}=10^{4} E_{1}$, where $E_{1}$ is the electric field in the dielectric layers. Thus, the discharge gap is set to less than $10 \mu \mathrm{m}$ to generate a high electrical field $\left(E_{2}=10^{7}-10^{8} \mathrm{~V} / \mathrm{m}\right)$ and assure the formation of nonthermal plasmas at a discharge voltage of around $1 \mathrm{kV}$.

In addition, the high electron temperatures ensure the production of chemically active species. In general, bacteria can be sterilized with an electric field of about $10^{4}-10^{5} \mathrm{~V} / \mathrm{m}$ [22].

\section{EXPERIMENTAL SETUP}

The experimental setup is shown in Fig. 3. Escherichia coli HB101 (gram-negative bacteria) and Bacillus subtilis JCB 20036 (gram-positive bacteria) cultures were used for our inactivation studies. Air or nitrogen were supplied through the flow meter and mixed with a 5 -mL culture suspension in the nebulizer. Cultured suspensions of Escherichia coli and Bacillus subtilis containing $10^{7}$ colony-forming units $/ \mathrm{mL}$ were prepared. 


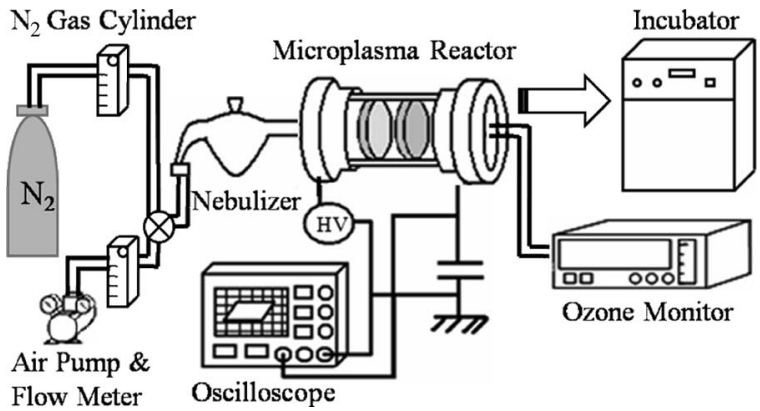

Fig. 3. Experimental setup for inactivation of microorganisms using a microplasma reactor.

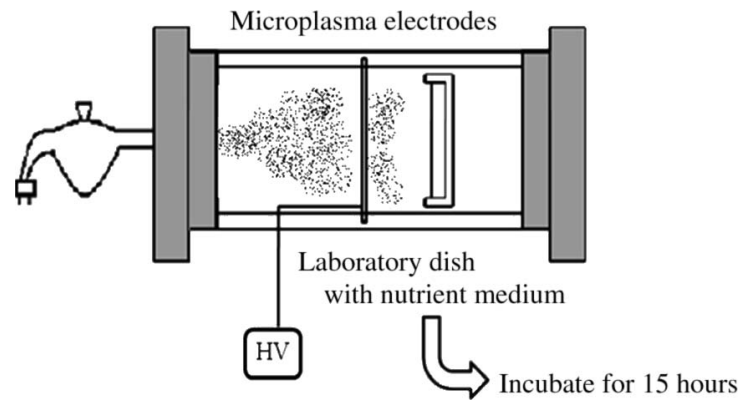

Fig. 4. Detailed assembly of the microplasma reactor.

The cultured suspensions were introduced into the microplasma reactor and sprayed through the electrode against a plate with nutrient agar medium at a gas-flow rate of $7 \mathrm{~L} / \mathrm{min}$. The desired gas-flow rate was adjusted by a pump or by the inner pressure of the nitrogen gas cylinder.

A digital oscilloscope (Tektronix, TDS 2014), a high-voltage probe (Tektronix, P6051), and an ac transformer (Tektronix, P6021) were used to measure the discharge voltage and corresponding discharge current.

The ozone concentrations were measured with an Ozone Monitor (Ebara Jitsugyo, EG-2001B), and the bacterial cultures treated by microplasma were incubated with agar medium in plates.

A high-voltage power supply (LECIP, M-1H) was used to apply a high-frequency ac voltage $(25 \mathrm{kHz}, 1 \mathrm{kV})$ to the microplasma electrodes.

Fig. 4 shows the details of the microplasma reactor. The inside diameter, the length, and the volume of the reactor were $48 \mathrm{~mm}, 180 \mathrm{~mm}$, and about $330 \times 10^{3} \mathrm{~mm}^{3}$, respectively. The sprayed suspensions were passed through the electrodes, and they accumulated on the culture plates. Experiments with and without microplasma were performed under equal conditions for the control.

After the plasma treatment of the bacteria and their collection on culture media, the culture plates were incubated in an incubator (Tokyo Rikakikai, LTI-700E) at $37^{\circ} \mathrm{C}$ for $15 \mathrm{~h}$ for Escherichia coli, and $30{ }^{\circ} \mathrm{C}$ for $18 \mathrm{~h}$ for Bacillus subtilis.

The inactivation rates were calculated from the averages (experiments were carried out in triplicate) by comparing the number of colonies with and without microplasma treatment. Some bacteria in water droplets were lost to the surface of the

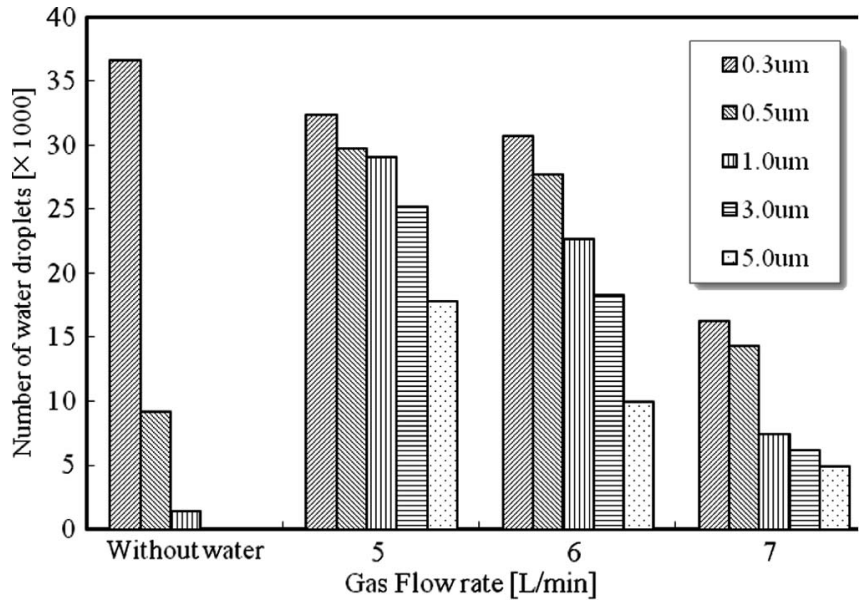

Fig. 5. Size distribution of water particles generated inside the nebulizer at gas-flow rates of 5,6 , and $7 \mathrm{~L} / \mathrm{min}$.

electrodes during the microplasma treatment by electrostatic precipitation.

\section{Characteristics of the PARTICles by the NebUlizer}

The diameters of the water particles formed by the nebulizer were measured by a laser particle counter (Kanomax, 3886).

The gas-flow rate was restricted to the range of 5-7 L/min because the pressure loss of the nebulizer was high. With no water added to the nebulizer, no droplets were formed. As shown in Fig. 5, our particle counter observed particles with diameters of only 0.3 and $0.5 \mu \mathrm{m}$. These particles could be the dust in the air. With water added to the nebulizer, water droplets with diameters ranging from 0.5 to $5 \mu \mathrm{m}$ were generated at the applied gas-flow rates of 5,6 , and $7 \mathrm{~L} / \mathrm{min}$. Smaller water droplets did not coalesce to form larger droplets because the number of $0.5-\mu \mathrm{m}$ droplets exceeds the number of $1.0-\mu \mathrm{m}$ droplets. Since the sizes of colon bacilli Escherichia coli HB101 and Bacillus subtilis JCB 20036 are about 0.5 to $2.5 \mu \mathrm{m}$, they are contained within the water droplets generated by the nebulizer.

\section{Electrical Characteristics}

In order to investigate the effect of spraying the microplasma electrodes with water, the discharge current was measured while spraying distilled water.

Fig. 6 shows an example of discharge waveforms. Current spikes [Fig. 6(b)] were observed at the steepest slopes of the discharge voltage [Fig. 6(a)]. This is a typical waveform of a dielectric-barrier discharge [19].

Fig. 7 shows the stability of the discharge current over time. Initially, the discharge current decreased slightly with time, and after $5 \mathrm{~min}$, the discharge current was stable. It is possible that a portion of the electrode surface was covered by water, which prevented the electrical discharge.

Such a phenomenon would result in the observed decrease in the discharge current.

Fig. 8 shows thermal camera pictures taken after $5 \mathrm{~min}$ of discharge. The temperature of the electrodes was almost the 


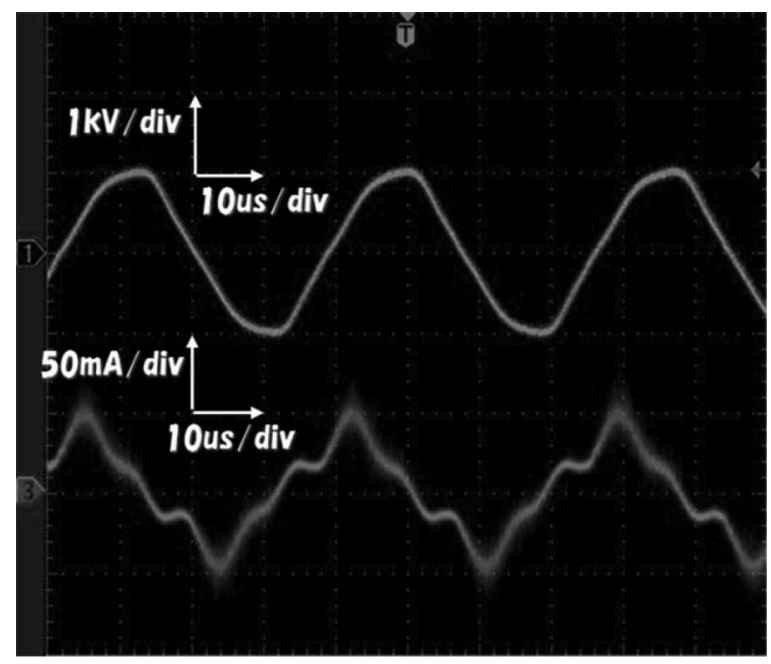

(a)

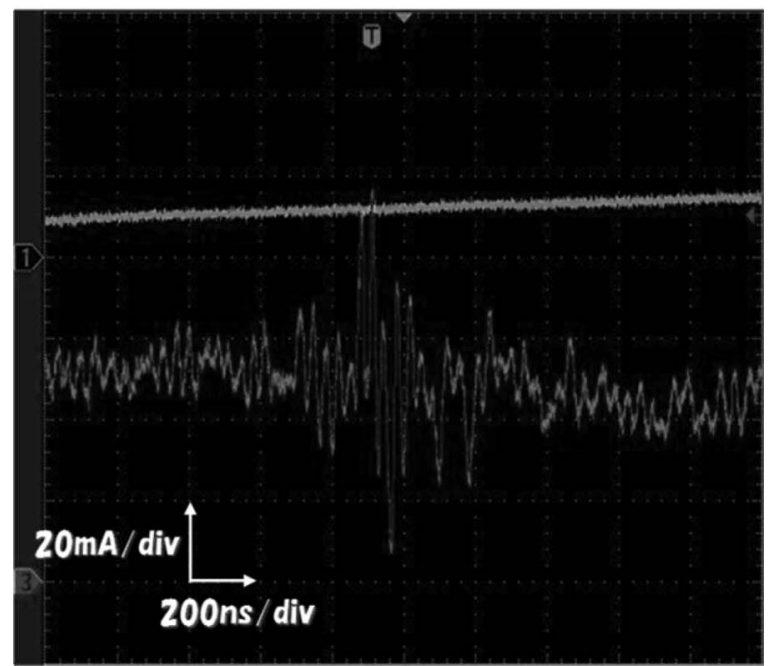

(b)

Fig. 6. Examples of discharge waveforms at $1 \mathrm{kV}$ using air as the carrier gas (a) Discharge voltage. (b) Discharge current.

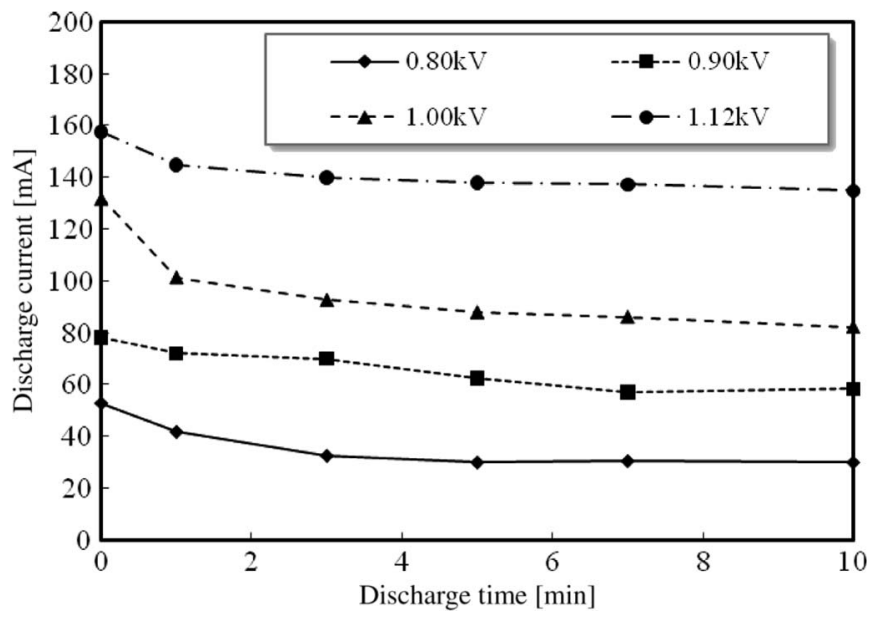

Fig. 7. Change of discharge current after discharge start with water spray.

same $\left(45^{\circ} \mathrm{C}\right)$ for both with and without sprayed water droplets. After $5 \mathrm{~min}$, the temperature of the electrodes and the discharge current were stabilized even with water droplets.
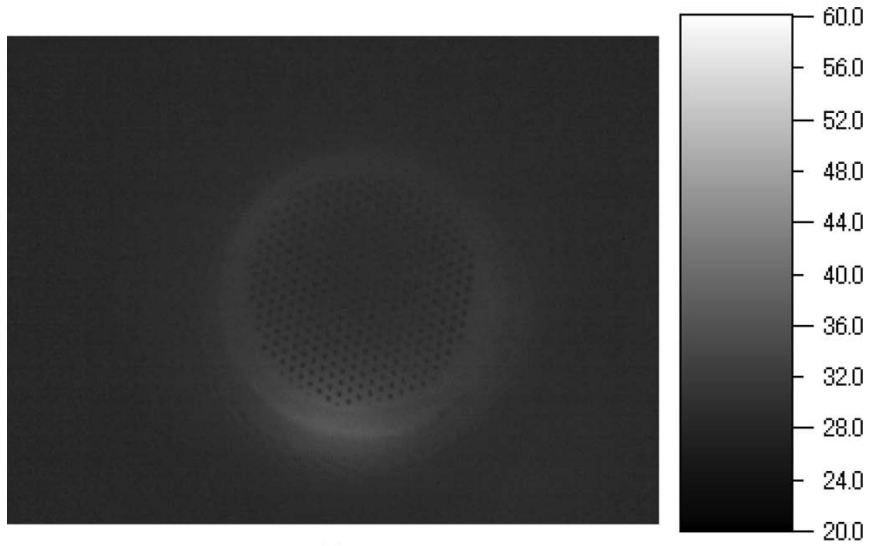

(a)

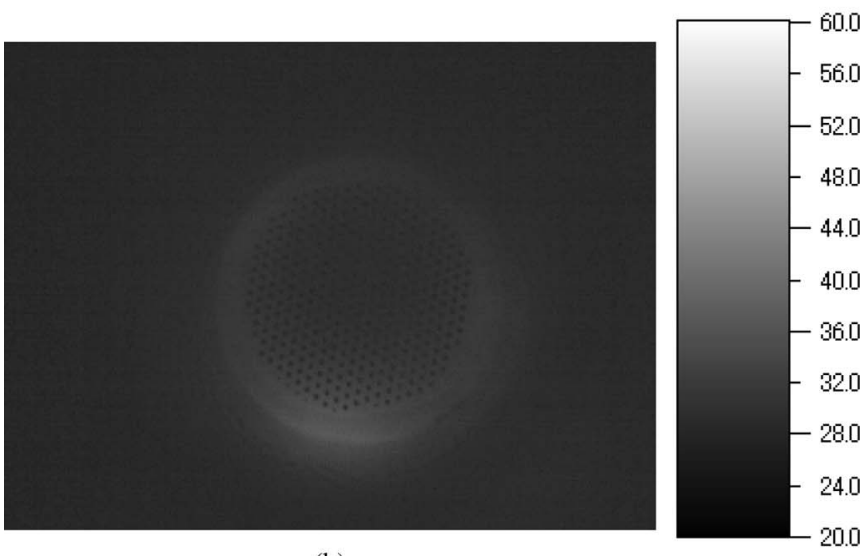

(b)

Fig. 8. Images of the thermal distribution of electrodes with and without distilled water droplets at a gas-flow rate of $7 \mathrm{~L} / \mathrm{min}$. (a) Thermal distribution of electrodes without water droplets. (b) Thermal distribution of electrodes with water droplets.

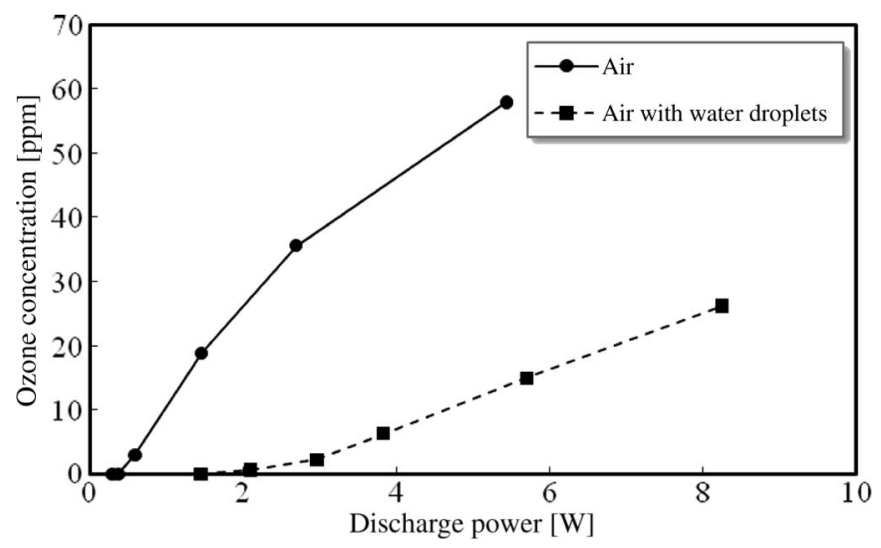

Fig. 9. Ozone concentration increases with discharge power both with and without water droplets at a gas-flow rate of $5 \mathrm{~L} / \mathrm{min}$.

Water droplets sprayed by the nebulizer are considered to have a minor influence on the discharge phenomena.

\section{OZONE GENERATION}

The concentrations of ozone generated by the microplasma increased with discharge power at a gas-flow rate of $5 \mathrm{~L} / \mathrm{min}$, as shown in Fig. 9. Ozone concentrations increased almost linearly with discharge power with no water droplets present. 


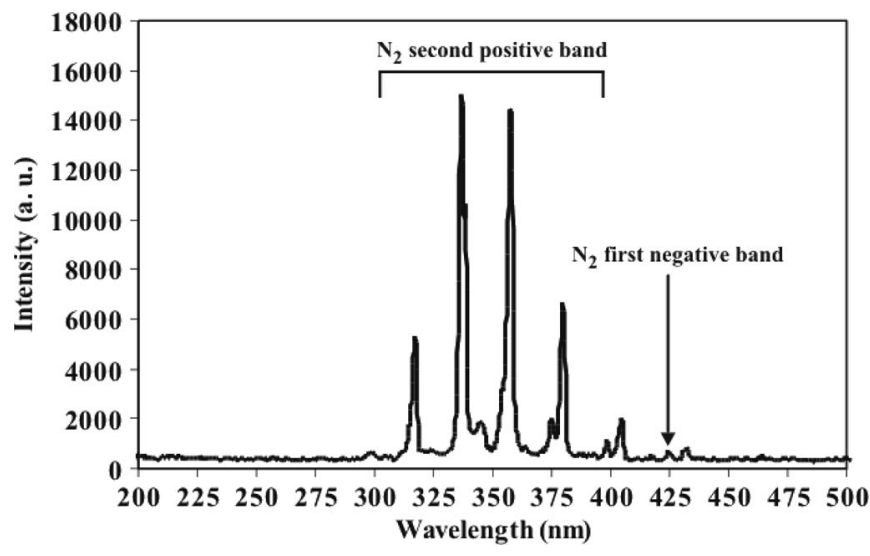

Fig. 10. Emission spectrum of the microplasma discharge in $\mathrm{N}_{2}$. Gas-flow rate was set at $5 \mathrm{~L} / \mathrm{min}$.

With water droplets present, the flowing gas was cooled down and condensed with iced water before measuring the ozone concentration for accurate measurements. The ozone concentrations were lower than for the same discharge power without water droplets due to the reaction by water [19]. Optical measurements discussed in the next section did not show any ozone peaks in the microplasma since the ozone is generated in the afterglow region of the discharge section.

Ozone is generated by a three-body slow reaction of free radical atomic oxygen and the ozone also dissociated by electron and atomic oxygen [23], [24].

\section{UV LIGHT EMISSION BY MICROPLASMA}

UV light emissions from microplasma were observed to confirm the effect of UV light on inactivation process of bacteria [20]. The emission spectra were measured by an intensified charge-coupled device (ICCD) camera (Ryoushi-giken, SMCP-ICCD 1024 HAM-NDS/UEmV), a spectrometer (Ryoushi-giken, VIS 351), and by a photomultiplier tube (Hamamatsu Photonics, R3896). A pulse generator (Tektronix, AFG 3021B) was used to trigger the ICCD camera and the Marx generator consisting of semiconductor switches. A Marx generator with four-stage MOSFET switches was used as the high-voltage supply for the microplasma electrodes. The spectrum was observed at $-1.4 \mathrm{kV}$ with a pulsewidth of $500 \mathrm{~ns}$ and a frequency of $1 \mathrm{kHz}$. The gas-flow rate of dry nitrogen was set at $5 \mathrm{~L} / \mathrm{min}$. Data obtained from the ICCD camera were transferred to a computer for analysis.

The emission spectrum of the microplasma discharge in $\mathrm{N}_{2}$ shown in Fig. 10 shows peaks of $\mathrm{N}_{2}$ second positive band system $\left(\mathrm{N}_{2} \mathrm{SPS}\right)$ and $\mathrm{N}_{2}$ first negative band system $\left(\mathrm{N}_{2} \mathrm{FNS}\right)$. The spectrum indicates the generation of active molecular nitrogen species in the microplasma discharge [25].

The elementary processes (1) and (2) describe the radiation kinetics for the SPS of nitrogen with a wavelength of $337.1 \mathrm{~nm}$ and at atmospheric pressure. [26].

The excitation of nitrogen molecules in the ground state by direct electron impact is described by

$$
e+\mathrm{N}_{2}\left(X^{1} \Sigma_{g}^{+}\right)_{v=0} \rightarrow \mathrm{N}_{2}\left(\mathrm{C}^{3} \pi_{u}\right)_{v^{\prime}=0}+e \quad(\Delta E=11 \mathrm{eV}) .
$$

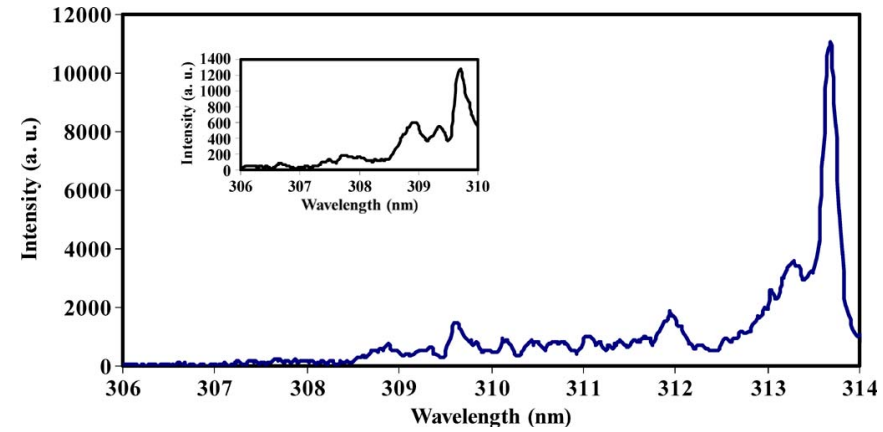

Fig. 11. Emission spectrum of $\mathrm{OH}$ in microplasma discharge with nitrogen and water droplets using a nebulizer. Gas-flow rate was set at $5 \mathrm{~L} / \mathrm{min}$. Emission spectra was observed at $-1.2 \mathrm{kV}$. The other conditions were the same as described in Fig. 10.

The spontaneous radiation of nitrogen in the excited state is described by

$$
\mathrm{N}_{2}\left(\mathrm{C}^{3} \pi_{u}\right)_{v^{\prime}=0} \rightarrow \mathrm{N}_{2}\left(\mathrm{~B}^{3} \pi_{g}\right)_{v^{\prime \prime}=0}+h v \quad\left(\tau_{0}^{C}=40 \mathrm{~ns}\right) .
$$

Water droplets from the nebulizer were entrained in the nitrogen gas that entered the chamber to confirm another active species in the microplasma discharge. Fig. 11 shows the emission spectrum of nitrogen with entrained water droplets. The gas-flow rate was set at $5 \mathrm{~L} / \mathrm{min}$. The UV light emission confirmed active species such as $\mathrm{OH}$ radicals around 307 to $309 \mathrm{~nm}$, as shown in Fig. 11 [25], [27]. UV light emissions from $316 \mathrm{~nm}$ and higher wavelengths were also observed, which affect the inactivation process of bacteria [28], [29]. The combination of UV light and active species could have contributed to the inactivation of bacteria.

\section{INACTIVATION By MicROPLASMA}

From these experiments, the basic characteristics of microplasma, such as discharge current, discharge power, and ozone generation in air, were obtained. Inactivation of Escherichia coli and Bacillus subtilis were experimentally investigated at a gas-flow rate of $7 \mathrm{~L} / \mathrm{min}$ by using microplasma electrodes. Ambient air and nitrogen were used to compare the effect of the oxidization effect of ozone and to confirm the effect of high electric field and UV radiation from microplasma.

Figs. 12-15 show photographs of the culture plates of treated Escherichia coli and Bacillus subtilis incubated for $15 \mathrm{~h}$ after treatment with a microplasma using air or nitrogen as the carrier gas. A decrease of the number of colonies was observed when the discharge voltage increased in both air plasma and nitrogen plasma. The inactivation process for bacteria may occur between the electrodes or in the space near the electrodes after passing through the holes in the electrodes.

Because of some limitations of the experimental setup, some colonies gathered at the lower edge of the nutrient medium and were difficult to count. Therefore, these uncountable colonies were excluded, and colonies near the center of the dish were used for comparison.

Fig. 16 shows the inactivation rates of Escherichia coli versus discharge voltages for the carrier gases, air and nitrogen, 


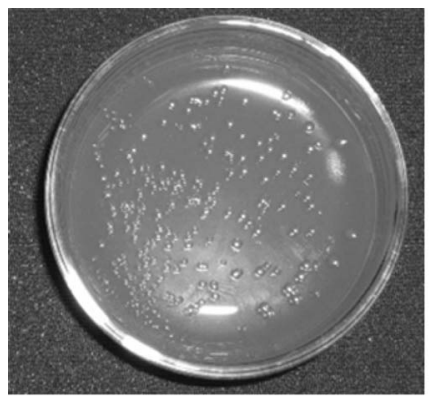

(a)

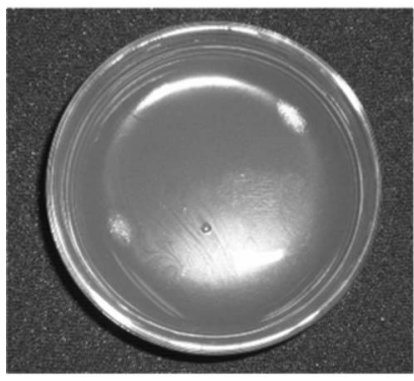

(c)

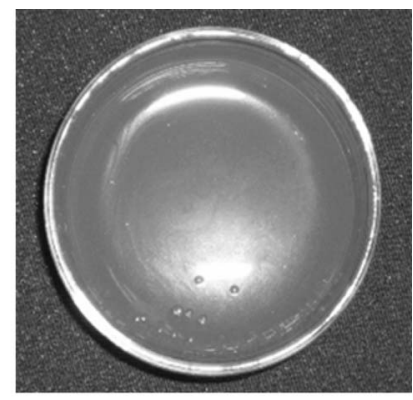

(b)

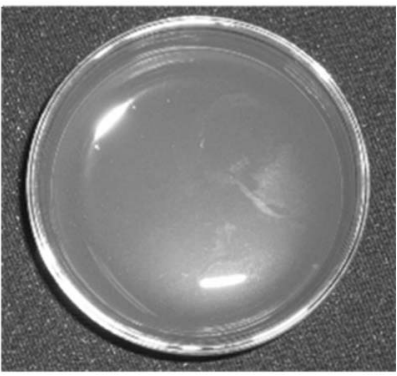

(d)
Fig. 12. Images of the Escherichia coli treated samples by microplasma after $15 \mathrm{~h}$ of incubation. Carrier gas is air at a gas-flow rate of $7 \mathrm{~L} / \mathrm{min}$. After the treatment by microplasma at (d) the discharge voltage of $1.08 \mathrm{kV}$, no colonies are observed. (a) Without discharge. (b) Discharge voltage of $0.90 \mathrm{kV}$. (c) Discharge voltage of $1.02 \mathrm{kV}$. (d) Discharge voltage of $1.08 \mathrm{kV}$.

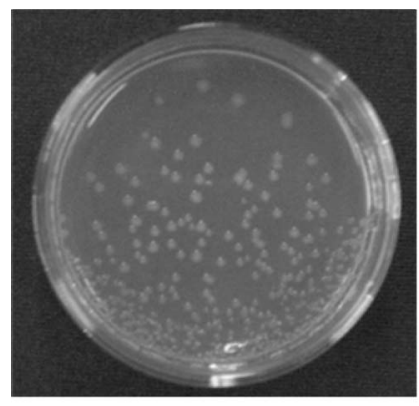

(a)

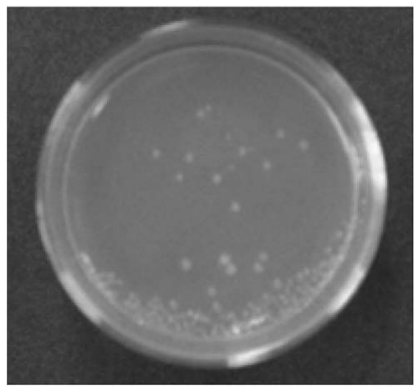

(c)

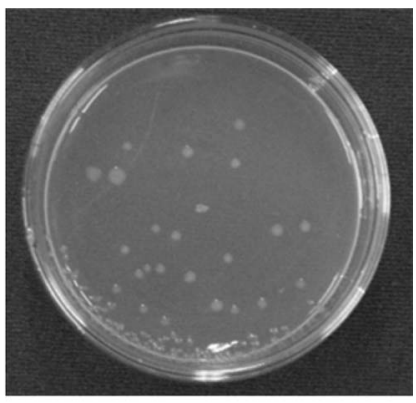

(b)

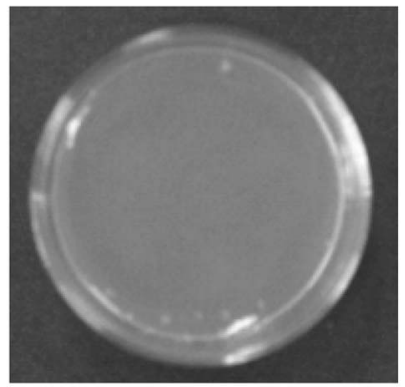

(d)
Fig. 13. Images of the Escherichia coli treated samples by microplasma after $15 \mathrm{~h}$ of incubation. Carrier gas is nitrogen at a gas-flow rate of $7 \mathrm{~L} / \mathrm{min}$. Few colonies still exist after the treatment by microplasma at (d) the discharge voltage of $1.15 \mathrm{kV}$. (a) Without discharge. (b) Discharge voltage of $0.76 \mathrm{kV}$. (c) Discharge voltage of $0.90 \mathrm{kV}$. (d) Discharge voltage of $1.15 \mathrm{kV}$.

respectively. When nitrogen was the carrier gas, the inactivation rate had the maximum value of $77 \%$ corresponding to a discharge voltage of $1.15 \mathrm{kV}$. Ozone was not formed during the discharge in the presence of nitrogen, and the inactivation of Escherichia coli could be considered to be due to the effects

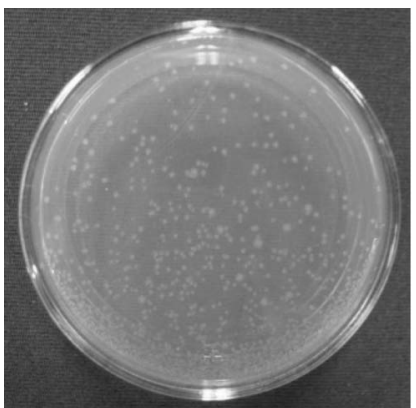

(a)

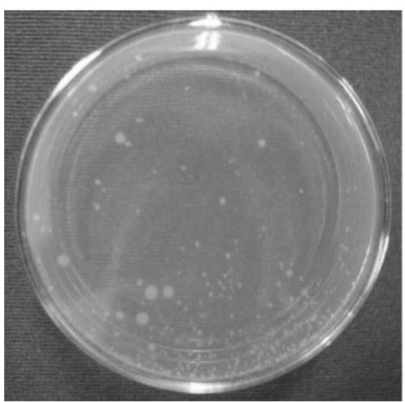

(c)

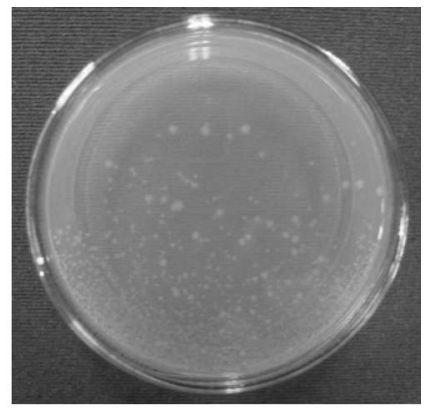

(b)

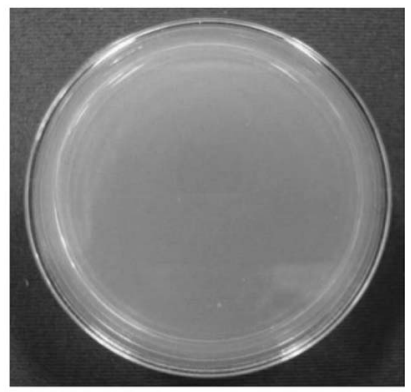

(d)
Fig. 14. Images of the Bacillus subtilis treated samples by microplasma after $15 \mathrm{~h}$ of incubation. Carrier gas is air at a gas-flow rate of $7 \mathrm{~L} / \mathrm{min}$. Few colonies still exist after the treatment by microplasma at (d) the discharge voltage of $1.07 \mathrm{kV}$. (a) Without discharge. (b) Discharge voltage of $0.77 \mathrm{kV}$. (c) Discharge voltage of $0.85 \mathrm{kV}$. (d) Discharge voltage of $1.07 \mathrm{kV}$.

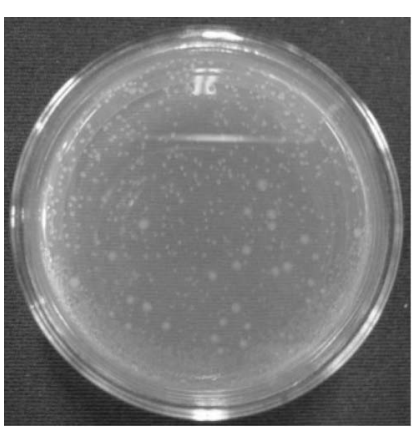

(a)

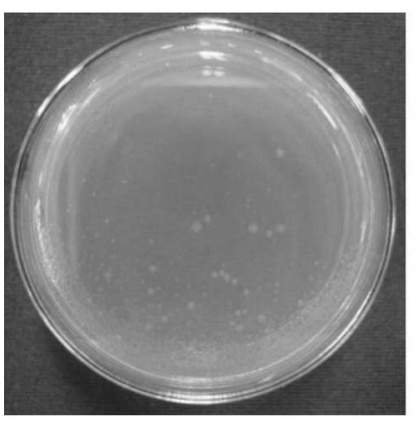

(c)

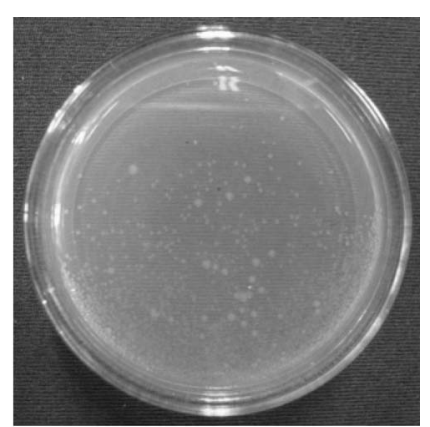

(b)

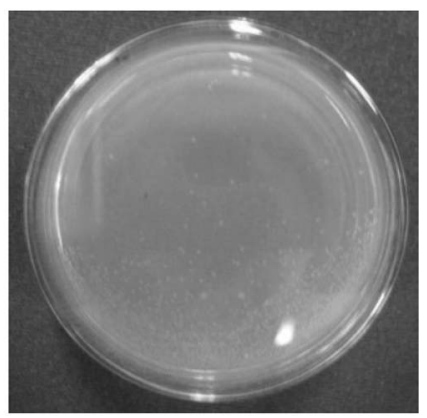

(d)
Fig. 15. Images of the Bacillus subtilis treated samples by microplasma after $15 \mathrm{~h}$ of incubation. Carrier gas is nitrogen at a gas-flow rate of $7 \mathrm{~L} / \mathrm{min}$. Few colonies still exist after the treatment by microplasma at (d) the discharge voltage of $0.96 \mathrm{kV}$. (a) Without discharge. (b) Discharge voltage of $0.67 \mathrm{kV}$. (c) Discharge voltage is $0.81 \mathrm{kV}$. (d) Discharge voltage of $0.96 \mathrm{kV}$.

of high electric field, excited nitrogen ions, active species such as $\mathrm{OH}$, and $\mathrm{UV}$ radiation by microplasma, as shown in Figs. 10 and 11. 


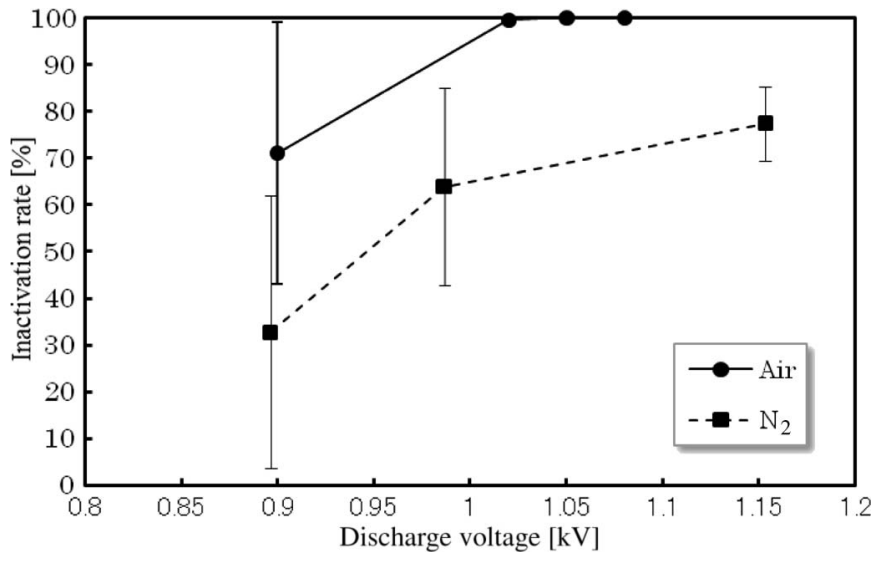

Fig. 16. Comparison of inactivation rate of Escherichia coli with air and nitrogen plasma.

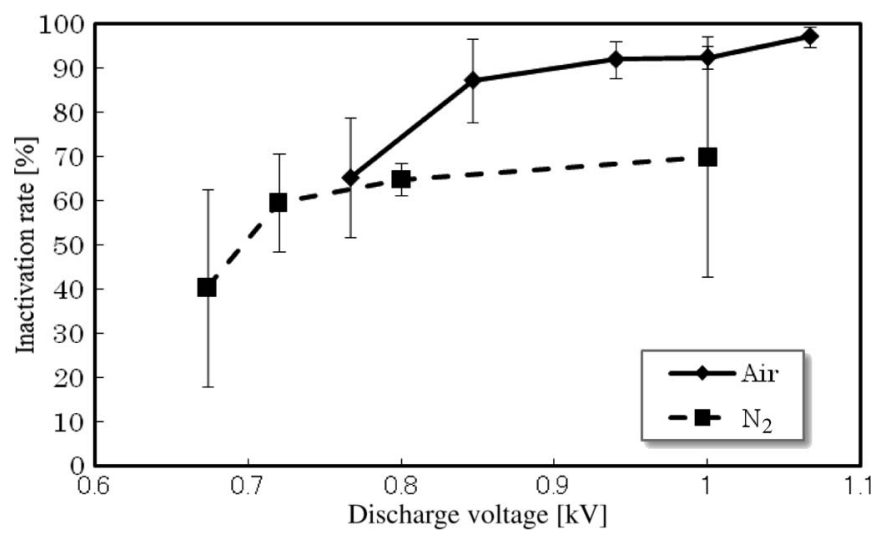

Fig. 17. Comparison of inactivation rate of Escherichia coli with air and nitrogen plasma.

In the case of the air as carrier gas, the inactivation rate was $100 \%$ at $1.05 \mathrm{kV}$. The higher inactivation rates obtained after air-plasma treatment were due to the combined effects of ozone, other active species, high electric field, and UV radiation by microplasma. In particular, the effect of UV on deoxyribonucleic acid (DNA) and the ozone on cell wall are well known [30], [31].

Fig. 17 shows the inactivation rate of Bacillus subtilis versus discharge voltages for the carrier gases, air and nitrogen, respectively.

In the case of air as carrier gas, the inactivation rate had a maximum value of $97 \%$ at $1.07 \mathrm{kV}$, and when nitrogen was the carrier gas, the maximum inactivation rate was $70 \%$ at $1 \mathrm{kV}$. These results are similar to the results of the inactivation of Escherichia coli due to the effects of ozone and active species existing in air plasma.

More effective results were obtained for the inactivation of Escherichia coli (gram-negative bacteria). It is possible that the lower inactivation of Bacillus subtilis (gram-positive bacteria) is caused by its relatively impermeable cell walls, which have a thickness in the range of 22 to $25 \mathrm{~nm}$. The cell wall of gram-positive bacteria is composed of peptidoglycan and secondary polymers. Gram-negative bacteria have thin peptidoglycan layers $(2-3 \mathrm{~nm})$ plus an overlying lipid-protein bilayer

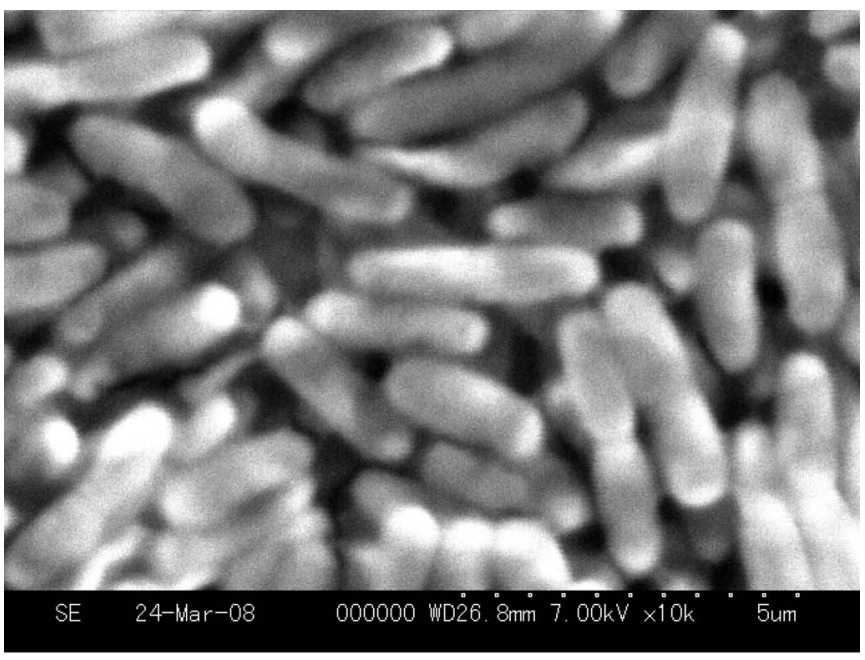

(a)

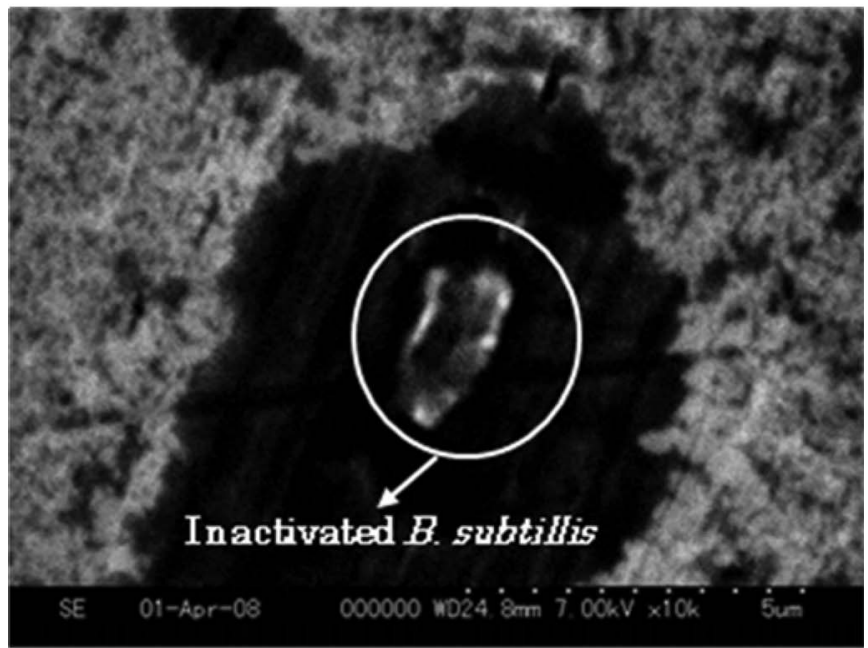

(b)

Fig. 18. Images of Bacillus subtilis by SEM. (Gas-flow rate $7 \mathrm{~L} / \mathrm{min}$, discharge voltage $=1 \mathrm{kV}, \mathrm{N}_{2}$ : carrier gas). (a) Living Bacillus subtilis $(\times 10000$ photograph taken by SEM). (b) Sterilized Bacillus subtilis by nitrogen plasma $(\times 10000$ photograph taken by SEM).

(7-8 nm) known as the outer membrane [31]-[33]. Although the results show that the inactivation rates for gram-positive and gram-negative bacteria are different, detailed studies should be done to explore the mechanisms responsible for the different survival rates. If the mentioned differences in the structure of the cell walls or other processes are responsible for the different inactivation rates, they need to be clarified in future studies.

Fig. 18 shows the images of Bacillus subtilis before and after inactivation by nitrogen plasma. The images were taken by a scanning electron microscope (SEM, Hitachi, S-3000 N). An aluminum foil was disinfected and cleaned with alcohol to collect and transfer the incubated bacteria on the medium surface, as shown in Fig. 18(a).

The image of Fig. 18(b) shows the treated bacteria, Bacillus subtilis by microplasma (gas-flow rate is $7 \mathrm{~L} / \mathrm{min}$, discharge voltage $=1 \mathrm{kV}, \mathrm{N}_{2}$ as carrier gas) on the medium surface which was also collected by using the aluminum foil. It shows how the cell wall of the bacteria or its shape was affected 
by the microplasma discharge. In particular, active radical species has etching effect to break their cell wall, and UV affects the DNA directly to cut their structure [31].

\section{CONCLUSION}

In this study, the inactivation of Escherichia coli and Bacillus subtilis using microplasma electrodes was experimentally investigated. The following conclusions are drawn from the series of experiments reported in this paper.

1) Other researchers report [22] that general bacteria can be inactivated with an electric field of about $10^{4}-10^{5} \mathrm{~V} / \mathrm{m}$. Thus high-intensity electric fields of $10^{7}-10^{8} \mathrm{~V} / \mathrm{m}$, which can be obtained by microplasma discharge, can be an inactivation mechanism for both Escherichia coli and Bacillus subtilis. A partial inactivation can be achieved using microplasma even without ozone in nitrogen as carrier gas.

2) A stable discharge was obtained using an applied voltage in the range $0.8-1.1 \mathrm{kV}$. A stable discharge was obtained even with some water present on the electrodes from droplets formed using a nebulizer that were sprayed against the electrodes.

3) The inactivation effect was confirmed at a relatively low discharge voltage of $0.9 \mathrm{kV}$, using either air or nitrogen as carrier gas.

4) The inactivation rate of both bacteria, Escherichia coli and Bacillus subtilis, increased as the discharge voltage increased with air and nitrogen used as carrier gases.

5) For Escherichia coli, a 100\% inactivation was obtained at $1.05 \mathrm{kV}$ with the application of air as carrier gas. Under otherwise equal conditions but with nitrogen as carrier gas, the inactivation rate decreased to $77 \%$ at $1.15 \mathrm{kV}$. The inactivation of bacteria could be considered as the combination effects of high electric fields, UV radiation, ozone, and active radicals formed inside the microplasma.

6) For Bacillus subtilis, the inactivation rate was $97 \%$ at $1.07 \mathrm{kV}$ and with air as carrier gas. When the carrier gas was nitrogen, an inactivation rate of $70 \%$ was obtained at $1 \mathrm{kV}$. The higher rates obtained with air as carrier gas were due to the presence of the ozone and oxidative radicals.

7) The higher inactivation rates obtained for Escherichia coli compared with Bacillus subtilis were possibly due to the different characteristics of the cell walls of grampositive and gram-negative bacteria, which have different thicknesses and chemical compositions.

8) Emission spectrometry was carried out to confirm the UV light and active species generated from microplasma. UV light ranging from $316 \mathrm{~nm}$ to a higher wavelength was observed which was mainly emitted from $\mathrm{N}_{2}$ only in nitrogen gas.

Emission by $\mathrm{OH}$ radicals ranging from 306 to $309 \mathrm{~nm}$ was also observed, when nitrogen and water droplets flowed through the microplasma electrode.

\section{ACKNOWLEDGMENT}

The authors would like to thank Prof. Nakasaki, Prof. Doura, and Dr. Baldermann of Shizuoka University for the fruitful discussions.

\section{REFERENCES}

[1] Q. Z. Wang, N. Sakai, and T. Hanzawa, "Numerical analysis of heat transfer of canned liquid foods containing fibers or particles during sterilization," J. Chem. Eng. Jpn., vol. 33, no. 5, pp. 703-708, 2000.

[2] S. Kobayashi, T. Murata, and K. Terai, "High intensity UV emission from cold-cathode mercury-argon lamps," Jpn. J. Appl. Phys., vol. 38, no. 7B, pp. 4605-4607, Jul. 1999.

[3] T. Hayakawa, A. Kuroiwa, E. Higashi, and K. Nakano, "Photoinduced bactericidal effect of Titania thin film against Legionella Pneumophila," Med. Bull. Fukuoka Univ., vol. 34, no. 2, pp. 71-81, 2007.

[4] M. Nagatsu, F. Terashita, and Y. Koide, "Low-temperature sterilization with surface-wave-excited oxygen plasma," Jpn. J. Appl. Phys., vol. 42, no. 7B, pp. 856-859, Jul. 2003.

[5] N. Hayashi, W. Guan, S. Tsutsui, T. Tomari, and Y. Hanada, "Sterilization of medical equipment using radicals produced by oxygen/water vapor RF plasma," Jpn. J. Appl. Phys., vol. 45, no. 10B, pp. 8358-8363, 2006.

[6] H. Ghomi, M. S. Rahman, P. R. Chalise, Y. Hayashi, M. Watanabe, A. Okino, T. Ano, M. Shoda, and E. Hotta, "Experimental investigation of effect of low-energy pulsed atmospheric electron beam on bacterial cells," Jpn. J. Appl. Phys., vol. 44, no. 12, pp. 8698-8701, 2005.

[7] T. Ito, Y. Murayama, M. Suzuki, N. Yoshimura, K. Iwano, and K. Kudo, "Evidence for sterilization of Saccharomyces Cerevisiae K 7 by an external magnetic flux," Jpn. J. Appl. Phys., vol. 31, no. 6A, pp. 676-678, Jun. 1992.

[8] T. C. Montie, K. Wintenberg, and K. Roth, Jr., "An overview of research using the one atmosphere uniform glow discharge plasma (OAUGDP) for sterilization of surfaces and materials," IEEE Trans. Plasma Sci., vol. 28, no. 1, pp. 41-50, Feb. 2000.

[9] K. Kitano, H. Aoki, and S. Hamaguchi, "Radio-frequency-driven atmospheric-pressure plasmas in contact with liquid water," Jpn. J. Appl. Phys., vol. 45, no. 10, pp. 8294-8297, 2006.

[10] M. Laroussi, G. S. Sayler, B. B. Glascock, B. McCurdy, M. E. Pearce, N. G. Bright, and C. M. Malott, "Images of biological samples undergoing sterilization by a glow discharge at atmospheric pressure," IEEE Trans. Plasma Sci., vol. 27, no. 1, pp. 34-35, Feb. 2004.

[11] F. J. Trompeter, W. J. Neff, O. Franken, M. Heise, M. Neiger, S. Liu, G. J. Pietsch, and A. B. Saveljew, "Reduction of bacillus subtilis and aspergillus niger spores using nonthermal atmospheric gas discharges," IEEE Trans. Plasma Sci., vol. 30, no. 4, pp. 1416-1423, Aug. 2002.

[12] M. Tanino, W. Xilu, K. Takashima, S. Katsura, and A. Mizuno, "Sterilization using dielectric-barrier discharge at atmospheric pressure," Int. J. Plasma Environ. Sci. Technol., vol. 1, no. 1, pp. 102-107, 2007.

[13] X. Deng, J. Shi, and M. G. Kong, "Physical mechanisms of inactivation of bacillus subtilis spores using cold atmospheric plasmas," IEEE Trans. Plasma Sci., vol. 34, no. 4, pp. 1310-1316, Aug. 2006.

[14] S. Guceri and A. Fridman, "Plasma assisted decontamination of biological and chemical agents," in NATO Science for Peace and Security Series A: Chemistry and Biology. New York: Springer Science, 2008.

[15] H. Yu, S. Perni, J. J. Shi, D. Z. Wang, M. G. Kong, and G. Shama, "Effects of cells surface loading and phase of growth in cold atmospheric gas plasma inactivation of Escherichia coli K12," J. Appl. Microbiol., vol. 101, no. 6, pp. 1323-1330, Dec. 2006.

[16] X. T. Deng, J. J. Shi, G. Shama, and M. G. Kong, "Effects of microbial loading and sporulation temperature on atmospheric plasma inactivation of Bacillus subtilis spores," Appl. Phys. Lett., vol. 87, no. 15, p. 153901 , Oct. 2005.

[17] K. Shimizu, T. Sugiyama, and L. S. Manisha Nishamani, "Study of air pollution control by using micro plasma filter," IEEE Trans. Ind. Appl., vol. 44, no. 2, pp. 506-511, Mar./Apr. 2008.

[18] K. Shimizu, T. Sugiyama, L. S. Manisha Nishamani, and M. Kanamori, "Application of micro discharge for air purification," IEEJ Trans. Power Energy, vol. 127, no. 12, pp. 1269-1274, 2007.

[19] U. Kogelschatz, "Dielectric-barrier discharges: Their history, discharge physics, and industrial applications," Plasma Chem. Plasma Process., vol. 23, no. 1, pp. 1-46, Mar. 2003.

[20] K. Shimizu, M. Blajan, and T. Ishii, "Emission spectrometry of microplasma in NO/ $\mathrm{N}_{2}$ mixture," in Proc. PSS/SPP-26, 2009, pp. 510-511. 
[21] J. O. Noyce and J. F. Hughes, "Bactericidal effects of negative and positive ions generated in nitrogen on Escherichia coli," J. Electrostat., vol. 54, no. 2, pp. 179-187, Feb. 2002.

[22] S. Katsuki, "Bacteria decontamination by pulsed power," J. Plasma Fus. Res., vol. 79, no. 1, pp. 20-25, 2003.

[23] J. S. Chang, P. Lawless, and T. Yamamoto, "Corona discharge processes," IEEE Trans. Plasma Sci., vol. 19, no. 6, pp. 1152-1166, Dec. 1991.

[24] J. S. Chang, A. J. Kelly, and J. M. Crowley, Handbook of Elecrostatic Processes. Boca Raton, FL: CRC Press, 1995.

[25] Z. Machala, M. Janda, K. Hensel, I. Jedlovský, L. Leštinská, V. Foltin, V. Martišovitš, and M. Morvová, "Emission spectroscopy of atmospheric pressure plasmas for bio-medical and environmental applications," J. Mol. Spectrosc., vol. 243, no. 2, pp. 194-201, Jun. 2007.

[26] K. V. Kozlov and H.-E. Wagner, "Progress in spectroscopic diagnostics of barrier discharges," Contrib. Plasma Phys., vol. 47, no. 1/2, pp. 26-33, Feb. 2007.

[27] F. Liu, W. Wang, S. Wang, W. Zheng, and Y. Wang, "Diagnosis of OH radical by optical emission spectroscopy in a wire-plate bi-directional pulsed corona discharge," J. Electrostat., vol. 65, no. 7, pp. 445-451, Jun. 2007.

[28] J. M. C. Robertson, P. K. J. Robertson, and L. A. Lawton, "A comparison of the effectiveness of $\mathrm{TiO}_{2}$ photocatalysis and UVA photolysis for the destruction of three pathogenic micro-organisms," J. Photochem. Photobiol. A, Chem., vol. 175, no. 1, pp. 51-56, 2005.

[29] A. K. Benabbou, Z. Derriche, C. Felix, P. Lejeune, and C. Guillard, "Photocatalytic inactivation of Escherischia coli: Effect of concentration of $\mathrm{TiO}_{2}$ and microorganism, nature, and intensity of UV irradiation," Appl. Catalysis B, Environ., vol. 76, no. 3/4, pp. 257-263, Nov. 2007.

[30] B. D. M. Scott and E. C. Lesher, "Effect of ozone on survival and permeability of Escherichia coli," J. Bacteriol., vol. 85, no. 3, pp. 567-576, Mar. 1963.

[31] R. Stainer, J. Ingraham, M. Wheelis, and P. Painter, The Microbial World, 5th ed. New York: Prentice-Hall, 1986.

[32] T. Beveridge, "Use of the Gram stain in microbiology," Biotech Histochem., vol. 76, no. 3, pp. 111-118, May 2001.

[33] T. Beveridge and J. Davies, "Cellular responses of bacillus subtilis and Escherichia coli to the gram stain," J. Bacteriol., vol. 156, no. 2, pp. 846-858, Nov. 1983.

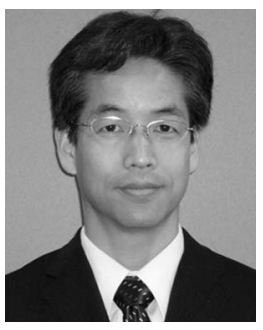

Kazuo Shimizu (S'93-M'00) was born in Hamamatsu, Japan, in 1969. He received the B.S., M.S., and Ph.D. degrees in electrical engineering from Toyohashi University of Technology, Toyohashi, Japan, in 1991, 1993, and 1996, respectively.

From April 1996 to 2002, he was an Assistant Professor in the Graduate School of Engineering and Frontier Science, The University of Tokyo, Tokyo, Japan. From 2002 to 2005, he was Secretary for Policy to a member of the House of Representatives (formerly Parliamentary Secretary for Land, Infrastructure and Transport). Since 2005, he has been an Associate Professor in the Innovation and Joint Research Center, Shizuoka University, Hamamatsu. His current interests are physics of microplasma and its applications for environmental protection.

Dr. Shimizu is a member of the Industry Applications Society of the Institute of Electrical Engineers of Japan and the Institute of Electrostatics Japan.

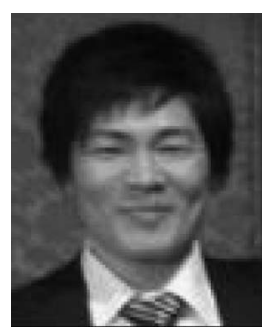

Masahiro Yamada was born in Gifu, Japan, in 1984. He received the B.S. and M.S. degrees from Shizuoka University, Hamamatsu, Japan, in 2007 and 2009, respectively.

He is currently with Toshiba Corporation, Tokyo, Japan.

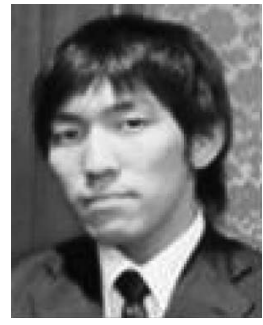

Masaki Kanamori was born in Yokosuka, Japan, in 1984. He received the B.S. and M.S. degrees from Shizuoka University, Hamamatsu, Japan, in 2007 and 2009, respectively.

$\mathrm{He}$ is currently with Toshiba Carrier Corporation, Tokyo, Japan.

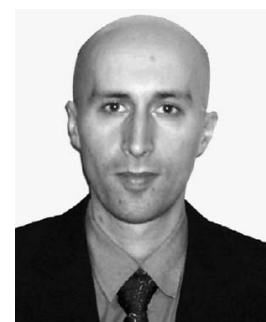

Marius Blajan was born in Cluj-Napoca, Romania, in 1974. He received the B.S. and M.S. degrees in electrical engineering from the Technical University of Cluj-Napoca, Cluj-Napoca, in 1997 and 2000, respectively, and the Ph.D. degree in electrical engineering jointly from the Technical University of Cluj-Napoca and the University of Poitiers, Poitiers, France, in 2006

$\mathrm{He}$ was an Engineer with an electrical company in Cluj-Napoca until October 2007. From November 2007 to March 2008, he was an Engineer with the Power Distribution Division, EMFESZ Romania. Since April 2008, he has been a Postdoctoral Researcher in the Innovation and Joint Research Center, Shizuoka University, Hamamatsu, Japan. His current interests are applications of nonthermal microplasma for $\mathrm{NO}_{\mathrm{x}}$ removal, indoor air purification, and sterilization.

Dr. Blajan is a member of the Institute of Electrostatics Japan and the Institute of Electrical Engineers of Japan. 